\title{
Gradhiva
}

Revue d'anthropologie et d'histoire des arts

18 | 2013

Le monde selon l'Unesco

\section{Les hyper-lieux du patrimoine mondial}

The World Heritage hyper-sites

\section{David Berliner et Manon Istasse}

\section{OpenEdition}

Journals

Édition électronique

URL : http://journals.openedition.org/gradhiva/2732

DOI : 10.4000/gradhiva. 2732

ISSN : 1760-849X

\section{Éditeur}

Musée du quai Branly Jacques Chirac

\section{Édition imprimée}

Date de publication : 1 décembre 2013

Pagination : 124-145

ISBN : 978-2-35744-072-2

ISSN : 0764-8928

Référence électronique

David Berliner et Manon Istasse, «Les hyper-lieux du patrimoine mondial », Gradhiva [En ligne],

18 | 2013, mis en ligne le 01 décembre 2016, consulté le 30 avril 2019. URL : http://

journals.openedition.org/gradhiva/2732 ; DOI : 10.4000/gradhiva.2732 



\section{Les hyper-lieux du patrimoine mondial}

par David Berliner et Manon Istasse

En comparant les centres historiques de Luang Prabang au Laos et de Fès au Maroc, il s'agit de dégager, par-delà leurs particularités, les similarités entre ces deux sites inscrits sur la liste du patrimoine mondial de l'humanité. Dès lors que l'Unesco est entrée en jeu, ces scènes patrimoniales se sont complexifiées. Tourisme, relecture de l'histoire, repeuplement, gentrification, spéculations économiques, sentiment de dépossession vécu par les habitants, mais aussi rivalités politiques: la patrimonialisation internationale engendre de nouveaux conflits et enjeux pour les résidents de ces hyper-lieux. 


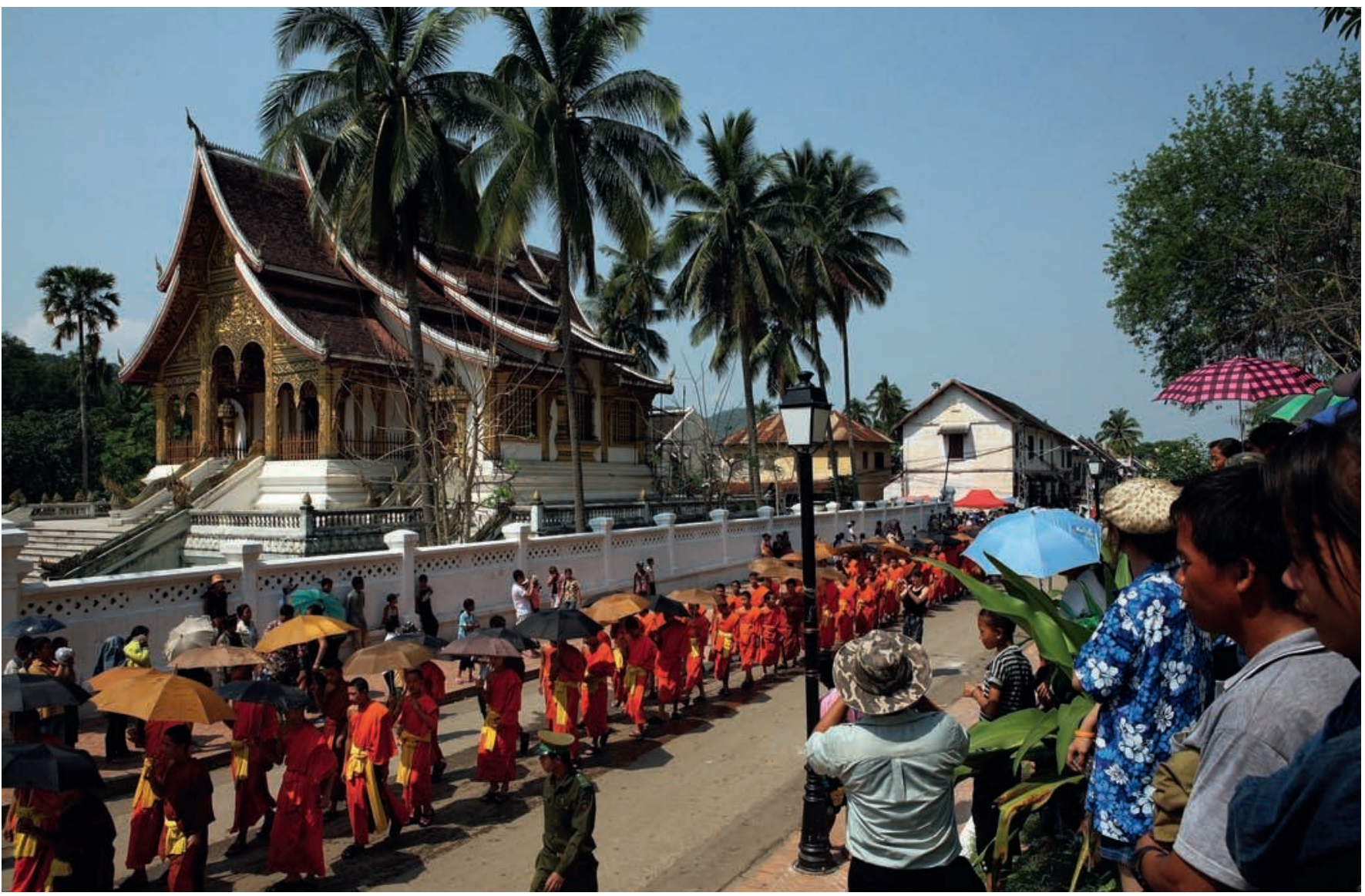

\section{page précédente}

et ci-dessus

fig. 1

Défilé des moines

bouddhistes lors du festival

de Songkran, Luang Prabang,

2008. () Chumsak Kanoknan/

Getty Images.
Les politiques de l'Unesco sont, la plupart du temps, appréhendées d'un point de vue utilitariste, en termes de réussite ou d'échec. Bien que nombre d'entre eux aient collaboré avec cette organisation internationale, les anthropologues ont souvent été les premiers à dénoncer son inadéquation aux réalités locales. En sortant des ornières d'un tel moralisme, nous proposons d'initier une réflexion comparée sur les effets pragmatiques de la reconnaissance d'un site par I'Unesco et, en particulier, sur la perception locale de cette institution et de ce qu'elle entreprend. Quelques recherches se sont déjà penchées, dans des lieux spécifiques, sur les conséquences économiques, politiques et sociales singulières de la patrimonialisation Unesco (parmi bien d'autres, Breglia 2006; Daly et Winter [éd.] 2011; Fontein 2006). Nous chercherons plutôt ici à nous éloigner d'une ethnographie aux détails foisonnants pour tenter de dégager les similarités émergeant entre sites préservés: I'Unesco (comprenons, ses membres et ses experts via leurs discours, écrits et actions), quand elle reconnaît un lieu, produit-elle des effets standardisés inhérents à l'Organisation? S'il est bien entendu que chaque endroit possède ses caractéristiques propres, comment celles-ci rencontrent-elles le processus de standardisation patrimoniale engendré par l'Unesco?

'Indonésie et le Maro dans son Observer l'islam (1992).

2. Pour une réflexion éclairée sur le comparatisme, voir Detienne (2000)
Un peu comme Clifford Geertz examinant une "drôle de paire ${ }^{1}$ ", comparons deux sites inscrits sur la liste du patrimoine mondial ${ }^{2}$. Fès et Luang Prabang ont de nombreux points communs. Ce sont deux villes royales et 


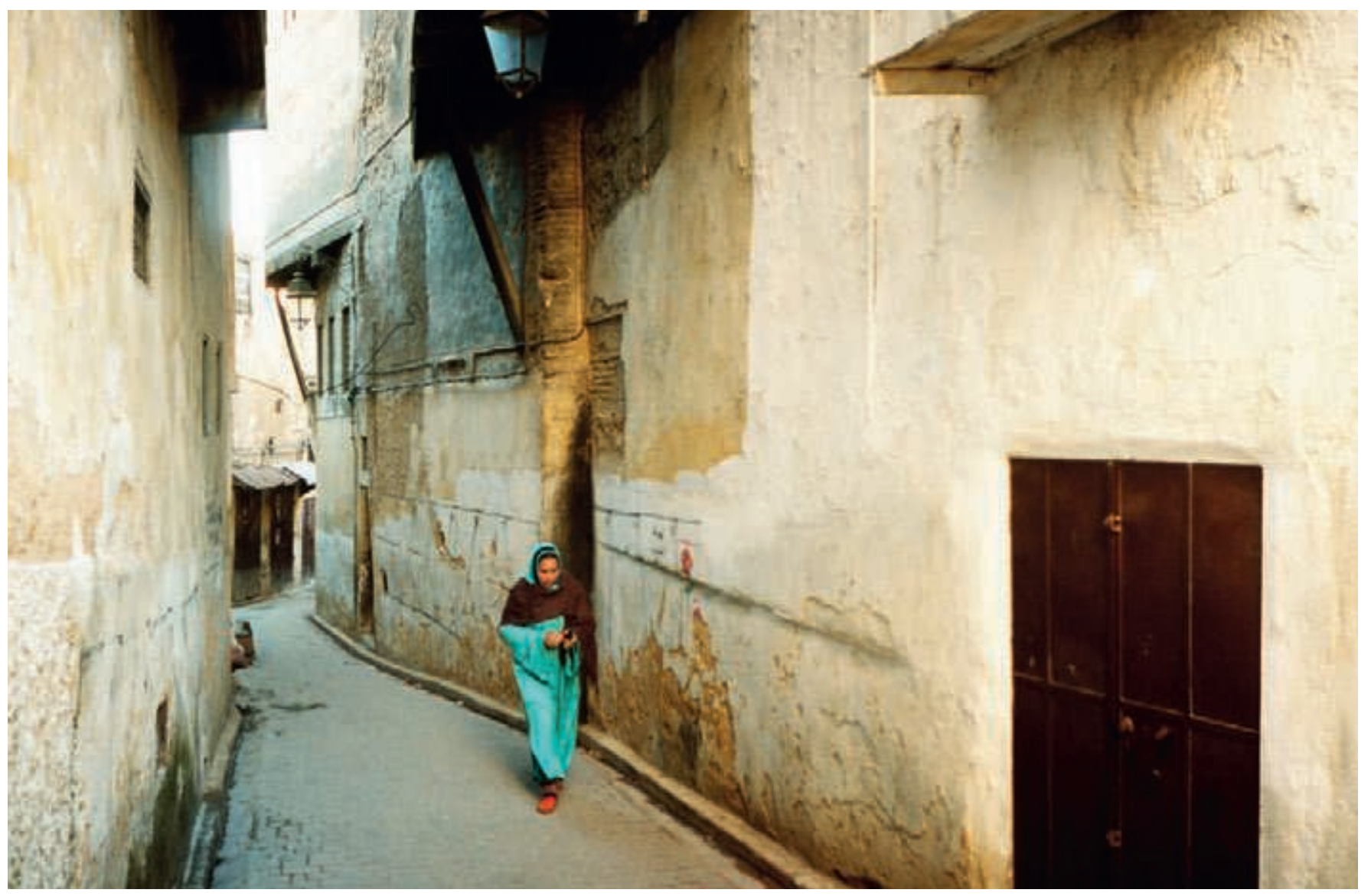

impériales, dont l'histoire officielle commence pour la première en 808 , lorsqu'un descendant du prophète Mohammed fonde «la plus ancienne ville du Maroc » et donc sa première capitale, au XIv ${ }^{e}$ siècle pour la seconde, quand Fa Ngum, son premier roi, y établit le royaume de Lane Xane sur un territoire alors occupé par des populations khmou (l'un des groupes ethniques du Laos). D'un point de vue sociologique, les deux villes ont été occupées, et le sont toujours, par diverses populations: Berbères, Arabes, Andalous musulmans et juifs, Français chrétiens, touristes et résidents étrangers, Sénégalais pour Fès; Laotiens du cru, mais aussi issus d'autres régions du Laos et d'autres groupes ethniques, Laotiens de la diaspora revenus d'exil, Vietnamiens, Chinois, expatriés, experts et touristes internationaux pour Luang Prabang.

Hauts lieux de la spiritualité, les deux villes sont des centres religieux reconnus. Fès brilla par la Qaraouiyine, à la fois mosquée et université (la plus ancienne du monde arabe), mais aussi grâce au sanctuaire de Moulay Idriss (le saint fondateur de la ville) et au mausolée de Sidi Ahmed Tijani (un saint soufi); tandis que Luang Prabang, où se trouve la fameuse statue du Bouddha, le Phra Bang, constitue un centre bouddhiste theravada très ancien dont les trente-quatre temples (au rang desquels figure le fameux Vat Xieng Thong) sont toujours habités par leurs moines. Les deux villes, soumises à la colonisation française depuis la fin $d u X X^{e}$ siècle, gardent des traces du passé colonial encore nombreuses et souvent mentionnées dans l'acte de reconnaissance patrimoniale. C'est à cette époque que les fig. 2

Femme dans une ruelle de la médina de Fès, s.d. (c) Panoramic Images/Getty Images. 
politiques de préservation du patrimoine culturel furent introduites au Maroc par le général résident Lyautey, alors même que l'École française d'Extrême-Orient jouait un rôle considérable dans l'inventaire architectural du patrimoine de Luang Prabang.

Plus récemment, les deux villes ont été déconsidérées au niveau national. Fès est considérée aujourd'hui par de nombreux Marocains comme arriérée et conservatrice. De son côté, Luang Prabang est vue depuis la Révolution socialiste de 1975 comme un bastion de la royauté. Au niveau international, en revanche, ces centres historiques ont été inscrits sur la liste du patrimoine mondial par l'Unesco, en 1981 pour Fès et en 1995 pour Luang Prabang. Enfin, depuis la fin des années 1990, ils connaissent un développement touristique important et reçoivent des investissements étrangers massifs, à l'instar d'autres sites tels que Marrakech et Essaouira au Maroc ou Angkor Vat au Cambodge.

\section{La présence absente de l'Unesco}

Que ce soit à Fès ou à Luang Prabang, la présence matérielle et symbolique de l'Unesco se manifeste par ce que nous appelons sa «présence absente». Par là nous souhaitons mettre l'accent sur le jeu entre, d'une part, sa relative visibilité dans l'espace urbain et institutionnel, et d'autre part l'opacité qui entoure sa présence pour les résidents du lieu. D'un point de vue institutionnel, les situations des deux villes sont différentes. À Fès, l'Unesco fut active au cours des années 1980 à travers l'envoi de consultants ayant participé à l'établissement du schéma directeur d'urbanisme et à la création d'un bureau dédié aux interventions techniques en médina (l'Ader, ou Agence de développement et de réhabilitation, une institution semi-publique composée d'experts et de techniciens marocains). Aujourd'hui, on ne trouve pas un seul bureau ni expert in situ. La dernière visite d'un expert missionné par l'Unesco remonte à 2009, pour y constater la menace que représentait un projet touristique et résidentiel dans une zone non ædificandi; l'unique représentant sur place est désormais l'inspecteur des monuments historiques, fonctionnaire au ministère de la Culture. Les traces matérielles de l'Unesco se limitent à un panneau d'autoroute mentionnant que le site est inscrit au patrimoine mondial ainsi qu'à des documents officiels en partie édités par l'Organisation (schémas d'urbanisme, rapports d'expertise et d'interventions techniques). Pourtant, celle-ci existe bien dans les discours institutionnels. Les membres des divers organismes chargés du patrimoine et de l'urbanisme utilisent ainsi l'argument du patrimoine mondial pour justifier des décisions patrimoniales et urbanistiques souvent impopulaires aux yeux des résidents: interdiction de faire telle modification architecturale au vu de l'inscription du site, autorisation d'utiliser du béton armé parce que l'Unesco en a favorisé l'utilisation dans une mosquée à Meknès, menace de faire appel au siège de Paris en cas de non-respect d'une zone protégée...

À Luang Prabang, en revanche, le territoire urbain est balisé par une série de pancartes signalant dès le départ que l'on pénètre dans un espace protégé par l'Unesco. Portant sur la préservation et la restauration de monuments religieux et d'habitations construits avant la seconde guerre mondiale, la politique patrimoniale s'exprime via la Maison du patrimoine, 
une structure nationale composée d'architectes laotiens et d'experts étrangers (français et liés à l'Unesco-Paris pour la plupart) qui veillent au respect du plan de sauvegarde et de mise en valeur et à celui de l'inventaire du patrimoine établi en 2000 par des architectes français (concernant 611 maisons, 34 temples bouddhistes, ainsi que des espaces naturels et aquatiques faisant partie intégrante du paysage de la ville ${ }^{\mathbf{3}}$ ). En étroite collaboration avec le siège du patrimoine mondial à Paris, la Maison du patrimoine conseille les propriétaires en matière de rénovation, vérifie les nouvelles constructions dans le périmètre protégé (notamment leur superficie et le matériel utilisé) et dénonce celles qui sont illicites; plus généralement, elle cherche à contrôler les investisseurs étrangers qui louent la plupart des maisons du centre-ville et les transforment en guesthouses et restaurants. Le bureau régional de l'Unesco à Bangkok a également lancé une série d'initiatives patrimoniales portant sur le patrimoine immatériel.

Alors que leur présence s'exprime selon des modalités différentes, I'Unesco et le patrimoine mondial constituent pourtant un «mythe» (Lahbil Tagemouati 2001) aux yeux de la plupart des habitants des deux villes. À Luang Prabang comme à Fès, ces derniers ne connaissent pas l'Unesco et ne manquent pas de confondre ses membres avec ceux de l'Ader ou de la Maison du patrimoine. Peu d'entre eux sont en mesure de citer une action entreprise par l'institution internationale, dont les politiques demeurent opaques. Un habitant de Fès souligne que «l'Unesco, on sait ce que c'est, mais on ne sait pas bien comment ça fonctionne ici », référant explicitement au manque d'informations relatives à l'Unesco et à ses actions, et implicitement aux possibles détournements d'argent opérés durant les projets de restauration. À Luang Prabang aussi, alors que l'on assiste à l'éveil contraint et forcé d'une conscience patrimoniale, il s'agit d'une institution mystérieuse, révérée parce que liée au respect du gouvernement laotien, mais dont il n'est question que lorsque les habitants sont confrontés à la rigueur de ses régulations ou à la supposée corruption des architectes qui y travaillent. De fait, dans les deux villes, lorsque les résidents parlent des politiques patrimoniales, c'est pour en dénoncer l'application difficile et les possibles malversations auxquelles elles donneraient lieu.

\section{Expertise et ruses patrimoniales}

Les formes que revêt l'expertise patrimoniale sont multiples. L'expert peut être aussi bien un architecte étranger mandaté par l'Unesco et établi sur place de manière permanente (comme c'est le cas à Luang Prabang), un membre d'une institution patrimoniale nationale (appartenant à un ministère ou à une administration locale) ou un spécialiste dépêché ponctuellement lors de missions de vérification (notamment par l'Icomos, I'International Council on Monuments and Sites, une ONG qui réalise la plupart des missions de vérification pour l'Unesco). Médiateurs cruciaux dans le processus de mise en patrimoine, ces experts sont notamment partie prenante dans la délivrance des autorisations pour réaliser des travaux et ouvrir un logement touristique. Leurs actions sont souvent critiquées par les habitants. À Fès, les propriétaires de logements touristiques dénoncent le manque de connaissances des membres des commissions d'experts nationaux dont le travail, pouvant se conclure par le blocage de la délivrance de l'autorisation, est vu comme un moyen de se faire de l'argent facile. À Luang Prabang,
3. Pour une description

du processus de patrimonialisation de Luang Prabang, voir Berliner (2010). 
4. Après l'indépendance du Maroc en 1957, de nombreuses familles fassies aisées ont quitté la médina pour s'installer dans les nouveaux centres politiques et économiques du pays comme Casablanca et Rabat, ou en ville nouvelle à Fès.

\section{ci-contre}

fig. 3

Construction d'une guesthouse sur les bords du Mékong,

Luang Prabang, 2004.

(c) AFP PHOTO/Laurent Fiévet. où l'expertise internationale est bien plus présente qu'à Fès, les experts étrangers sur place depuis des années, qui s'indignent de la transformation de la ville en un "Disneyland", sont décrits avec ironie par certains habitants comme «plus laotiens que les Laotiens eux-mêmes. lls voudraient nous apprendre comment être laotiens.»

S'ils parlent régulièrement de leur solitude, les experts ne sont pourtant pas isolés dans leur lutte patrimoniale. Autour d'eux se déploie une communauté d'individus, expatriés et élites locales, qui se sentent concernés par la patrimonialisation du lieu. À Fès, par exemple, il n'est pas rare de rencontrer un résident cultivé qui, bien que niant avec modestie ses compétences, déploie une rhétorique de l'expertise. «Bon, je ne suis pas un expert, mais ces zelliges [mosaïques] sont à première vue d'origine", déclare un Français dirigeant une entreprise de restauration de maisons. De fait, certains étrangers vivant en médina et actifs dans la restauration architecturale sont souvent consultés pour toute question relative à l'achat ou la datation d'une maison. À force d'y vivre et de se documenter, les propriétaires de maisons d'hôtes acquièrent une compétence patrimoniale sur l'architecture locale. Certaines élites marocaines possèdent également ce genre d'expertise, résultat de leur lien affectif au lieu (y avoir passé son enfance) ou de leur profession (historiens ou professeurs). De riches membres de familles fassies ayant vécu en médina ${ }^{4}$ sont actifs dans sa préservation et sa promotion, un moyen pour eux d'y maintenir une certaine présence, plus matérielle et économique que physique. Ainsi Karim Lamrani, via sa fondation éponyme, a pris en charge la restauration du caravansérail Nejjarine et sa gestion en tant que musée du bois.

À Luang Prabang, certains expatriés mais aussi des Laotiens issus de la diaspora (revenant s'installer définitivement au Laos après des décennies d'exil) et des élites locales développent des initiatives patrimoniales personnelles telles que des campagnes de sensibilisation destinées aux touristes (notamment sur le respect de la tranquillité lors des offrandes matinales aux moines), un musée présentant la diversité culturelle du pays ou encore des projets d'échanges internationaux d'artistes. Un Laotien issu de la famille royale, ayant vécu pendant vingt ans en France (où il dit s'être familiarisé avec l'ethnologie), a d'ailleurs créé un centre culturel dans le but de transmettre les arts de la région, non pas aux touristes, mais bien «aux jeunes Laotiens pour qu'ils apprennent la culture authentique de Luang Prabang, le tissage, les danses, l'orfèvrerie, les arts de cour. Ici, dans mon centre, on enseigne aux jeunes les bonnes manières et le bon comportement laotien. » Allergique au synthétique, aux tissus en provenance de Chine et aux vases en aluminium, le directeur du centre souhaite produire «à l'ancienne ", ce qui nécessite de "travailler avec les vieux artisans de l'époque royale". Autant d'actions qui, en marge de la patrimonialisation officielle du lieu, consacrent la destinée de Luang Prabang comme centre de préservation et de transmission culturelle sanctuarisé par l'Unesco.

Face à l'expertise patrimoniale et à la lourdeur des procédures administratives, les réactions des habitants constituent des «ruses » au sens de Michel de Certeau (1990), à savoir leurs tactiques du quotidien et leurs «mille manières de braconner» ( $p$. XXXVI). Prenons l'exemple de la restauration 


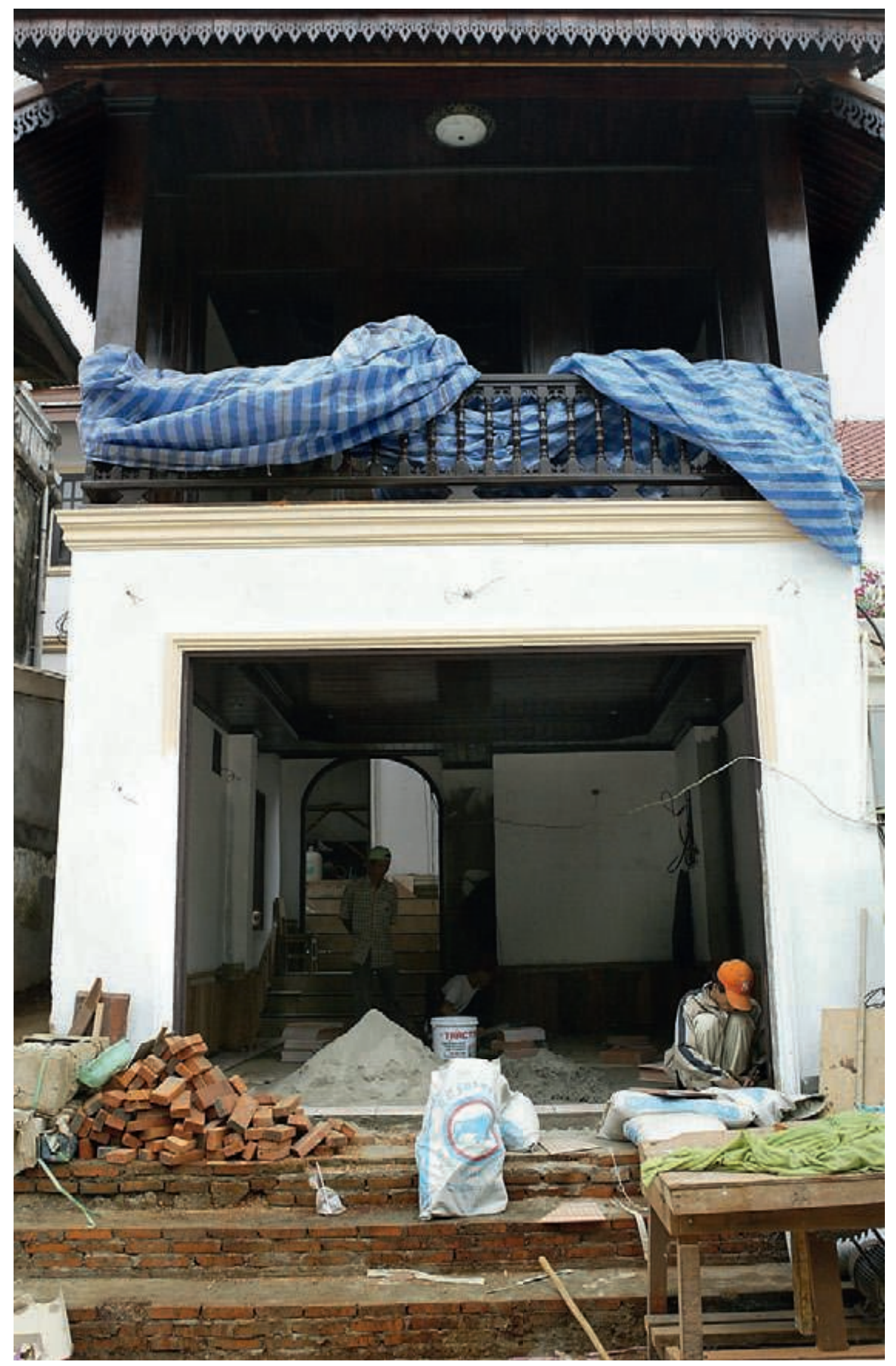




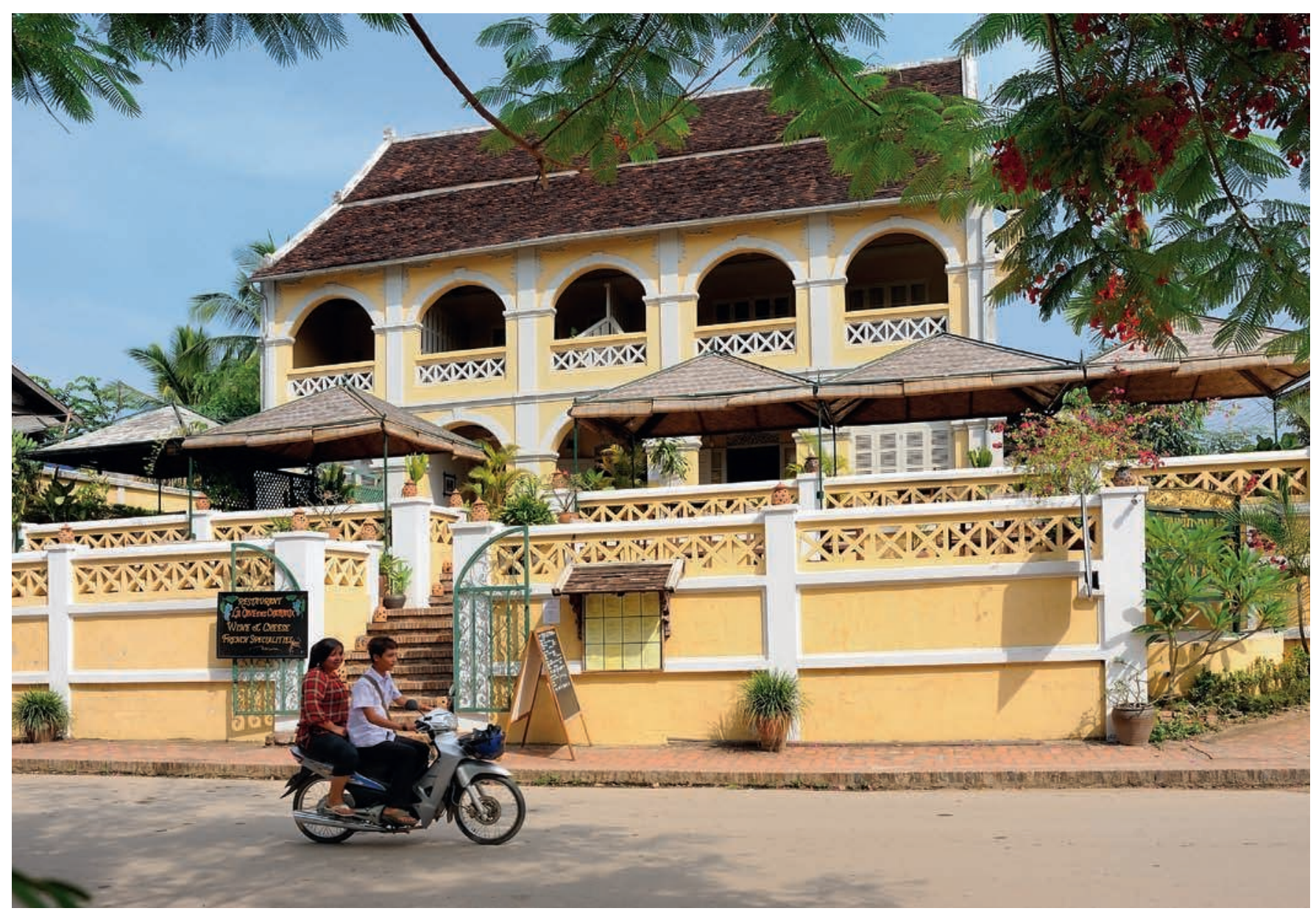

$\mathrm{fig}=4$

Rue de Luang Prabang, 2010.

(c) Christophe Boisvieux/Hemis . 
des maisons. À Fès comme à Luang Prabang, pour nombre de modifications intérieures ou extérieures de leur habitation, les résidents doivent faire une demande préalable d'autorisation de travaux auprès des autorités compétentes (la commune ou la Maison du patrimoine). Dans la pratique, ils ne manquent pas de détourner les normes en vigueur, et bon nombre de menus travaux (construction d'un mur, réfection de l'étanchéité d'une terrasse, etc.) sont effectués sans les autorisations nécessaires, coûteuses en temps et en argent. À Luang Prabang, l'organisation internationale a clairement contribué à créer chez les habitants un sentiment de dépossession de leurs droits de propriété: «Le patrimoine veut limiter nos droits. Ces terrains sont à nous. Avant on réparait comme on voulait, maintenant il faut demander l'autorisation à la Maison du patrimoine. " Aussi, alors que le plan de sauvegarde et de mise en valeur du centre-ville interdit formellement les vitres, les fenêtres récentes, les pots de fleurs, la coupe des arbres, les barrières devant les maisons et la laque sur le bois, nombreux sont ceux qui n'hésitent pas à enfreindre ces réglementations. Les résidents tendent à sur-occuper leurs terrains (pour y construire guesthouses et restaurants), tandis que les autorités locales ont été amenées à vendre certaines habitations classées à des investisseurs privés, et ce à l'encontre des régulations imposées par l'Unesco.

On retrouve des tactiques semblables à Fès où les propriétaires de maisons d'hôtes, et notamment les étrangers, ne mettent pas un point d'honneur à respecter le cahier des charges imposé par le ministère du Tourisme: ils n'hésitent pas à ajouter une cheminée, à choisir du mobilier européen et un style minimaliste ou à omettre les télévisions et minibars requis dans chaque chambre. D'autres habitants surélèvent les terrasses pour bénéficier d'une belle vue ou utilisent du béton pour refaire sols et murs. Bref, dans les deux contextes urbains prévaut chez les résidents le désir de "faire ce que l'on veut chez soi", attachés qu'ils sont à leur maison, lieu de vie souvent entretenu en dépit des règles officielles. À cet égard, les institutions patrimoniales sont avant tout perçues comme des instances qui empêchent de "faire ceci ou cela", et des sentiments de contrainte et une rhétorique du non-respect volontaire de certaines normes animent la plupart des discussions.

\section{Tourisme, investissements étrangers et gentrification cosmopolite}

Un autre aspect fondamental de l'unescoïsation, surtout dans les régions du monde les plus exposées à la précarité, est le lien qui existe désormais entre patrimoine mondial, tourisme et développement économique. Se joue ici le paradoxe des politiques de l'Unesco et de la patrimonialisation internationale: alors même que celles-ci visent à préserver des lieux (depuis la convention de 1972) et des pratiques culturelles (depuis la convention de 2003), elles produisent dans le même mouvement des effets dynamiques, innovants et destructeurs sur les lieux et les pratiques qui sont l'objet de la conservation. Faire d'un lieu un sanctuaire Unesco, c'est aussi rendre possible ou, selon le contexte, favoriser sa touristification et sa transformation en un espace aux frontières plus floues, un lieu désormais ouvert aux capitaux étrangers et à la circulation de catégories d'acteurs multiples aux imaginaires patrimoniaux et touristiques contrastés. 
En ce domaine, l'attitude de l'Unesco, notamment vis-à-vis du tourisme, s'est transformée à travers le temps (Cousin 2008), l'inscription au patrimoine mondial étant désormais pensée comme un outil d'essor économique et touristique (à condition que celui-ci se déploie dans le cadre d'un «développement durable»). Pourtant, les liens entre tourisme et patrimoine ne sont pas clairs. Selon Maria Gravari-Barbas et Sébastien Jacquot (2008), la chaîne qui relie inscription au patrimoine mondial et développement économique comporte de nombreux maillons mal connus, et l'inscription, bien qu'étant souvent un facteur de développement, n'est ni nécessaire ni suffisante.

Pragmatiques, les résidents de Luang Prabang ont bien compris que patrimoine et tourisme sont intimement liés et que «si on arrête de s'occuper du patrimoine ou si on nous retire le label Unesco, les touristes ne viendront plus ». La grande majorité d'entre eux s'accorde à reconnaître que leur vie a très positivement changé depuis dix ans. Tous expriment leur fierté à l'idée que leur ville soit reconnue internationalement et que des touristes viennent y dépenser leur argent. L'augmentation des ressources économiques locales est l'impact positif le plus souvent mentionné par les divers interlocuteurs, l'unescoïsation ayant créé de nombreux emplois, bien que de manière inégale, aussi bien en ville qu'à la campagne (parmi les propriétaires de guesthouses, les conducteurs de rickshaw et les producteurs d'artisanat ethnique). Dans le même temps, depuis sa reconnaissance patrimoniale, le centre-ville est l'objet d'investissements massifs de la part de membres de la "classe cosmopolite», des individus fortunés venant de Singapour, de Thaïlande, de Chine, de France et d'Australie, mais aussi des Laotiens aisés qui rénovent des maisons classées et construisent de nouveaux espaces pour y ouvrir restaurants et hôtels en s'inspirant du style «indochinois». Lieu charmant pour y séjourner et investir, le centre-ville de Luang Prabang se transforme peu à peu en un espace gentrifié, une marque à consommer (brand) engendrée par les logiques du capital international, vendue par des opérateurs touristiques sur la base de son unicité artificielle.

À Fès, la gentrification de la médina est principalement le fait de résidents étrangers (français, anglais, américains, australiens ou allemands) dont l'arrivée peut être attribuée à la saturation touristique de Marrakech et Essaouira (McGuinness 2006). Le mouvement d'achat de maisons initié à Marrakech dans les années 1980 a commencé à Fès à la fin des années 1990 pour atteindre un pic en 2005 et 2006, avant de retomber dès 2009 . Selon un architecte de la commune, sur les 14000 maisons de la médina, environ 500 appartiennent à des étrangers en tant que résidence secondaire, résidence principale ou maison d'hôtes (sur le même phénomène à Marrakech, voir Kurzac-Souali 2007). Cette présence étrangère a entraîné une hausse des prix de l'immobilier ainsi qu'un essor économique lié à l'accroissement de l'embauche dans les domaines de la restauration immobilière et de l'accueil touristique et au développement des bazars. Elle a également permis, par la réhabilitation de nombreuses maisons, de préserver la médina et de maintenir actifs certains corps de métiers traditionnels du bâtiment (mosaïstes, plâtriers, menuisiers). Pourtant, l'inscription de la médina au patrimoine mondial n'est pas, ou peu, mentionnée comme facteur ayant favorisé l'achat par ces résidents étrangers. 
La reconnaissance par l'Unesco est perçue comme une "plus-value» au sein d'un mouvement touristique plus général (Fès fait partie des circuits touristiques des villes impériales depuis le protectorat), mais elle n'en est pas le déclencheur comme ce fut le cas à Luang Prabang.

Une telle présence étrangère amène un sentiment de dépossession chez nombre de résidents marocains. Dépossession matérielle par la vente et la location massive de maisons à des non-Marocains; dépossession émotionnelle également, qui se manifeste notamment autour du trope du «retour du colon français» et de théories de la conspiration. À Fès, la colonisation n'est plus politique mais économique, et il faudra bientôt un «passeport» pour entrer en médina. Tandis qu'à Luang Prabang on raconte que "l'Unesco veut faire une meuang Falang uniquement ici» (littéralement une «ville française» et, par extension, une «ville d'Occidentaux»), une ville colonisée une seconde fois. Autant de discours qui révèlent le sentiment de désappropriation et l'incertitude ressentis par les habitants dans ce contexte désormais mondialisé qui attise, pour certains, une rhétorique du danger collectif où se mêlent patrimoine, Occident, tourisme et colonialisme.

\section{Une authenticité patrimoniale contestée}

Il est une autre question qui unit, souvent en les opposant, la pluralité des acteurs différemment engagés dans le processus de patrimonialisation à Fès et à Luang Prabang: celle de l'authenticité. De nombreuses études (Cohen 1988; Girard 2006; Heinich 2009) ont montré que l'authenticité est une notion fondatrice des entreprises patrimoniales et touristiques. Quand bien même celle-ci a fait polémique au sein de l'Unesco (notamment en 1994 lors de la conférence de Nara, au Japon, au cours de laquelle a été dénoncé son caractère eurocentrique), elle continue de motiver les pratiques de nombreux experts en patrimoine. À bien y regarder, dans ces espaces unescoïsés, elle fonctionne comme une catégorie relationnelle qui articule entre eux les discours savants des experts (de l'Unesco et des professionnels du patrimoine), des touristes, des locaux, des investisseurs étrangers et des opérateurs touristiques.

Au Maroc comme au Laos, l'authenticité des villes telle que promue par l'Unesco est celle d'un passé révolu que les habitants ne rencontrent au quotidien que comme la trace d'un temps ancien mais qui est bien, en revanche, ce que les touristes viennent chercher et trouvent en ces lieux. En effet, aussi bien à Fès qu'à Luang Prabang, c'est «l'esprit du lieu» qu'il s'agit de préserver avant tout, une notion désormais utilisée comme un concept opératoire par les experts de l'Unesco pour désigner l'ambiance spécifique qui se dégage et se ressent dans ces lieux historiques. D'un côté, une capitale religieuse marocaine qui respire la spiritualité, un lieu de vie intense aux populations hétéroclites, haut lieu d'un artisanat multiséculaire, bijou architectural possédant une longue histoire; de l'autre, l'enchantement de la mystique bouddhiste et de ses moines en robes couleur safran, les maisons coloniales qui rappellent l'Indochine et L'Amant de Marguerite Duras, le tout dans un écrin naturel époustouflant. Autant d'indices qui participent de l'objectification esthétique, entre émerveillement et dépaysement, caractéristique du regard touristique et patrimonial repris comme argument de vente par les commerçants laotiens et marocains ainsi que 


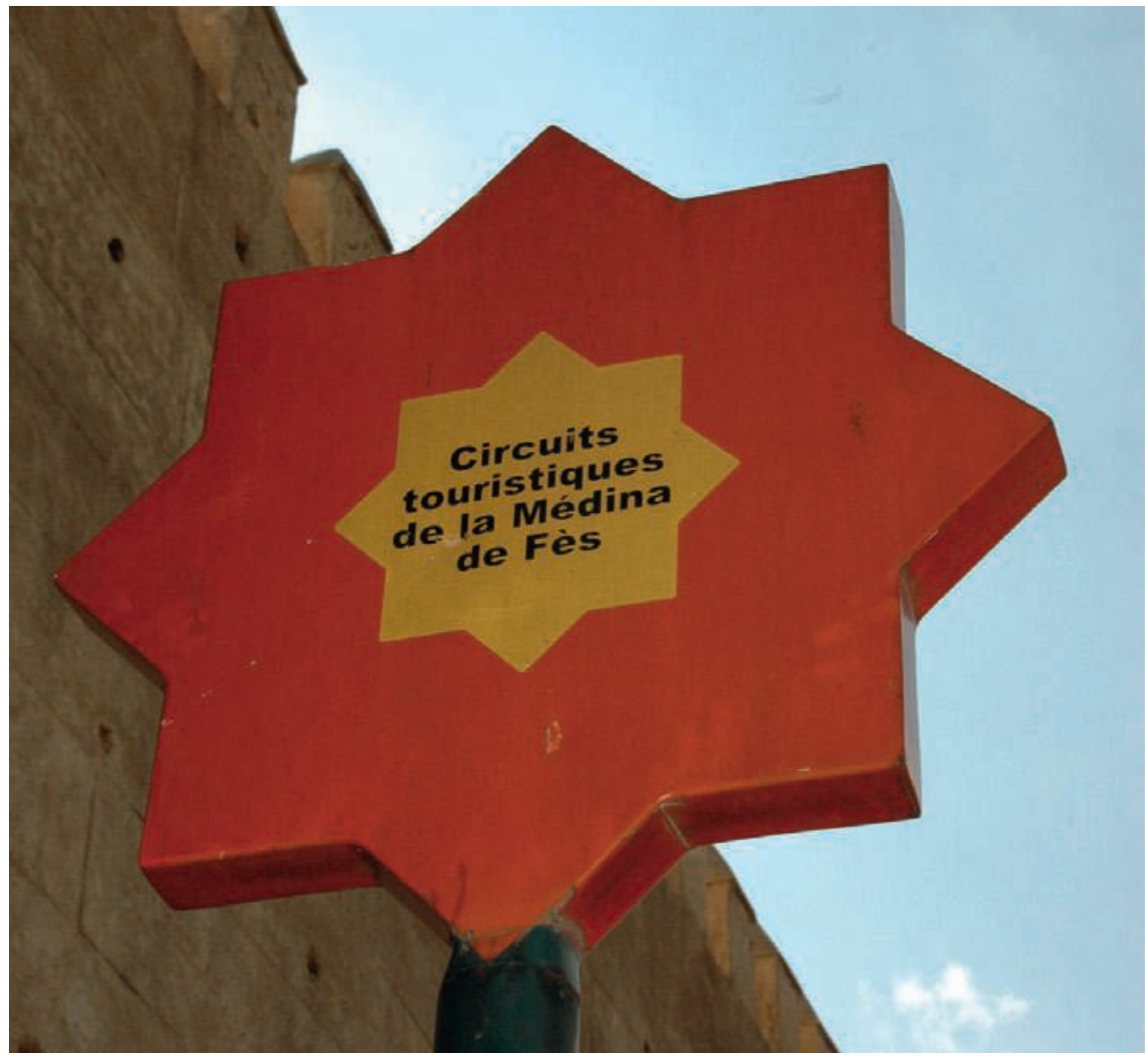

fig. 5

Signalétique dans les rues de

la médina de Fès, 2010.

(C) Mathias Chaillot. 


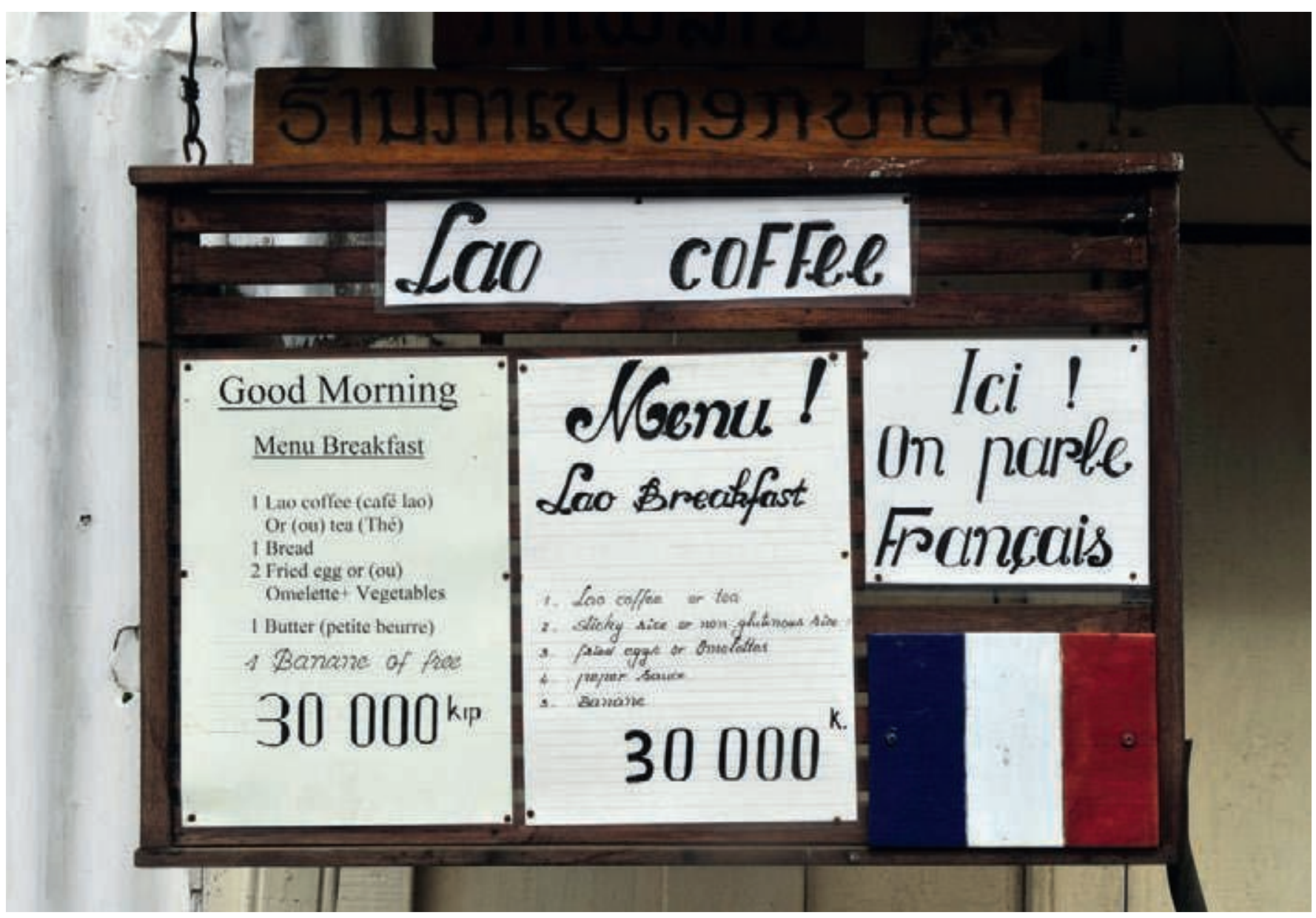

fig. 6

Menu d'un restaurant à Luang

Prabang, 2012. (C) Frédéric

Soreau / Photononstop. 
par les guides touristiques vantant le fonctionnement moyenâgeux de la médina et l'histoire bouddhiste de Luang Prabang. Plus encore que le cadre bâti, il s'agit donc de conserver un mode de vie «authentique » reposant sur les principes de distance temporelle (ce qui est ancien), spatiale (ce qui est exotique) et physique (ce que l'on ne vit plus): que seraient la médina et le centre-ville de Luang Prabang sans leurs habitants, si ce n'est un musée à ciel ouvert, sans âme?

Aux yeux des étrangers qui y habitent ou la visitent, la médina représente un patrimoine englobant aussi bien le bâti que les activités qui s'y déroulent et l'ambiance qui s'en dégage. Amateurs d'authenticité (le caractère non modifié depuis son origine) et de typicité (représentative d'un mode de vie), certains resteront en admiration devant un carreau de mosaïque, son procédé de fabrication et son insertion dans la décoration d'une maison là où les habitants marocains n'y verront que leur quotidien. L'idée de la médina comme espace culturel à préserver dans sa globalité ne tombe pas sous le sens, loin de là. En témoignent les multiples traductions en arabe marocain de la notion de patrimoine: warth (héritage familial et matériel qui se transmet des parents aux enfants), âthar (monument historique: édifice en ruine), taqalid (mode de vie, avec une distinction entre le mode de vie d'avant, disparu, et le mode de vie actuel), et tourath (patrimoine immatériel transmis depuis des générations). Aussi, en fonction des interlocuteurs, l'authenticité des lieux se décline-t-elle diversement. Pour certains elle se retrouve dans les styles architecturaux et décoratifs, selon une conception proche de la notion de typicité: c'est le style arabo-andalou de la ville, celui des riches fassis du passé (salon marocain, tissus colorés, tables basses) ou encore berbère (plus rural). Mais l'authenticité, ce sont également les souvenirs d'enfance des habitants et des élites locales parties s'installer dans les villes nouvelles, à Casablanca, à Rabat ou à l'étranger. Plus qu'un style architectural, l'authenticité devient ici nostalgie d'un âge d'or perdu, d'une époque où la religion était respectée et où les maisons n'étaient pas aussi chères qu'aujourd'hui.

Pour les résidents étrangers, en revanche, vivre à Fès, c'est habiter une « ville du Moyen Âge » car nombre d'entre eux disent y retrouver la même atmosphère et les mêmes éléments que ceux qu'ils associent au Moyen Âge occidental: les ânes dans les rues, les artisans qui travaillent dans leur boutique, le commerce de proximité, l'idée d'une ville qui fonctionne en parfaite autonomie. L'authentique est alors ce qui est «pur jus», inchangé depuis l'origine. Mais c'est aussi ce qu'il s'agit de vendre aux touristes de passage, sensibles à l'esprit médiéval de la médina. Si certains groupes de touristes se limitent à une visite des principaux bâtiments (musées, tanneries, ateliers), d'autres tentent d'être au plus près du «mode de vie authentique » en logeant chez l'habitant, en buvant le thé avec les commerçants ou en se promenant en solitaire dans le dédale de ruelles. Enfin, pour les architectes et autres professionnels de la restauration, l'authenticité a trait aux techniques de construction, se mêlant alors à la notion de tradition (faire comme on a toujours fait). Cependant, même pour eux, c'est aussi parfois ce qui s'apparente à de l'ancien, une authenticité de façade donc, davantage fondée sur le paraître que sur l'ancienneté avérée des éléments du patrimoine. 
Un tel «désajustement» (Heinich 2009: 76) autour de ce qui est authentique entre le regard des experts, des touristes et des habitants se retrouve au Laos. Les architectes de l'Unesco ne cessent de s'y confronter à la question de l'intact, du réel et de l'artifice, afin que la restauration soit la plus fidèle possible à ce qu'étaient jadis ces temples (dont certains furent construits au XVI ${ }^{e}$ siècle) et ces maisons. Par souci d'authenticité, pour recréer l'atmosphère d'antan (une entreprise que certains assimilent à l'œuvre d'un illusionniste), il faut, par exemple, restaurer ces lieux en utilisant uniquement des matériaux et des techniques anciens, ou encore effacer les réseaux électriques visibles et les affichages publicitaires dans le centreville. Empreinte de cette restorative nostalgia qui "signifie un retour à l'état d'origine » où «le passé n'est pas une durée mais une diapositive parfaite» (Boym 2001: 49, notre traduction), cette perspective eurocentrique est partagée par de nombreux touristes et par certaines élites locales, mais non par la majorité des résidents de Luang Prabang qui ne souhaitent pas tout garder à l'identique, préférant au contraire faire des adaptations modernes. Bref, se joue, aussi bien à Luang Prabang qu'à Fès, une scène désormais classique entre experts internationaux, expatriés et élites locales qui enferme les locaux, pourtant détenteurs d'une compétence esthétique qui leur est propre, dans le kitsch et l'incapacité à préserver leur propre héritage.

\section{Mémoires et temporalités contrastées}

Mais c'est sur la question de la temporalité et des rapports contrastés au passé et au futur que se dessinent les fractures les plus profondes entre les divers acteurs attachés à ces lieux patrimoniaux. L'inscription au patrimoine mondial peut contribuer à privilégier certains discours historiques et à en aplanir d'autres. À Luang Prabang, le passé patrimonialisé offert au regard touristique s'inspire d'une Indochine reconstituée principalement par le biais d'une sélection spécifique de monuments précoloniaux et coloniaux (français) avec lesquels la plupart des habitants de la ville ne s'identifient pas positivement. Tout d'abord, quand elles surgissent, les formes locales de la nostalgie ne ressemblent pas à celle qu'éprouvent les experts internationaux et les touristes étrangers: nostalgies royalistes, mémoires souffrantes de la révolution socialiste, regrets des habitudes d'antan et dénonciations de certaines conséquences néfastes du tourisme, notamment du tourisme sexuel (Berliner 2011). Ensuite, les expressions nostalgiques des habitants sont fermement encadrées par un discours sur l'avenir de leur espace urbain. La majorité d'entre eux ne se lamente pas de la disparition d'un passé idyllique qui aurait été meilleur mais souhaite voir "encore plus de touristes et d'avions". La plupart du temps, les attitudes locales vis-à-vis de la préservation sont plutôt une manière de prendre pied dans la modernité qu'une façon de s'en préserver.

Pour de nombreux Marocains, le patrimoine, vécu au quotidien, ne va pas parfois sans le désir de s'en défaire pour suivre le mouvement de la modernité. Ainsi, à Fès, les mémoires sont multiples, loin de l'image lisse promue par l'Unesco et les instances patrimoniales. Certains sont nostalgiques d'un mode de vie passé. Les souvenirs s'élaborent autour de la prière du vendredi à laquelle tous, y compris les jeunes garçons, assistaient parés de leurs plus beaux vêtements. Les écrivains racontent leur enfance en médina (La Boîte à merveilles d'Ahmed Sefrioui, Rêves de femmes 


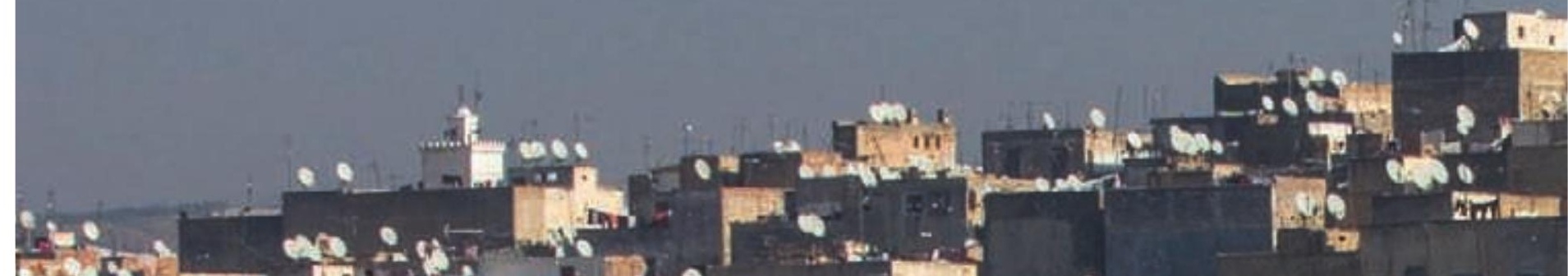

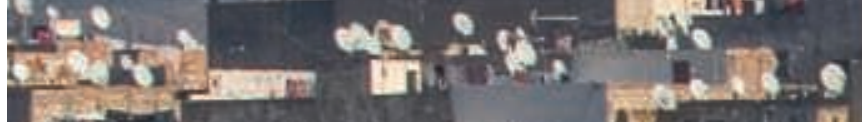

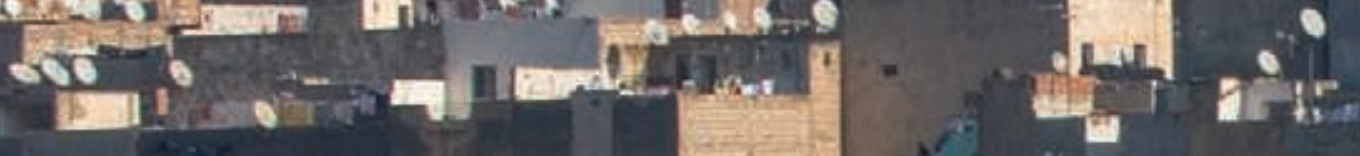
min

$\cos 0+20$ - coil and

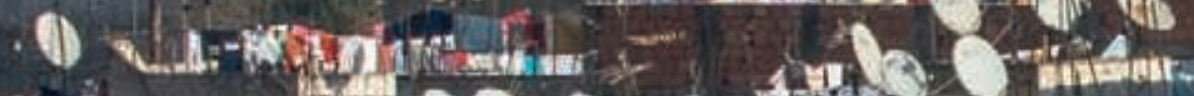

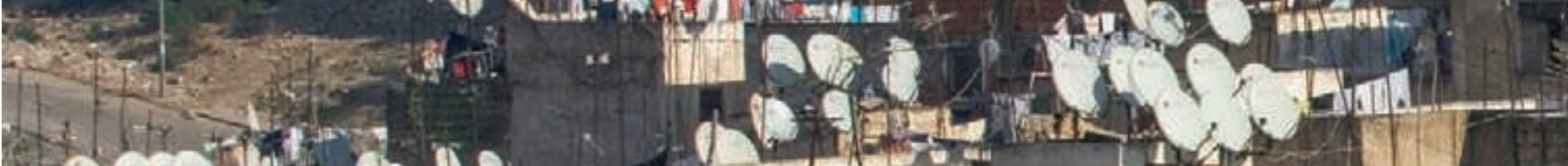

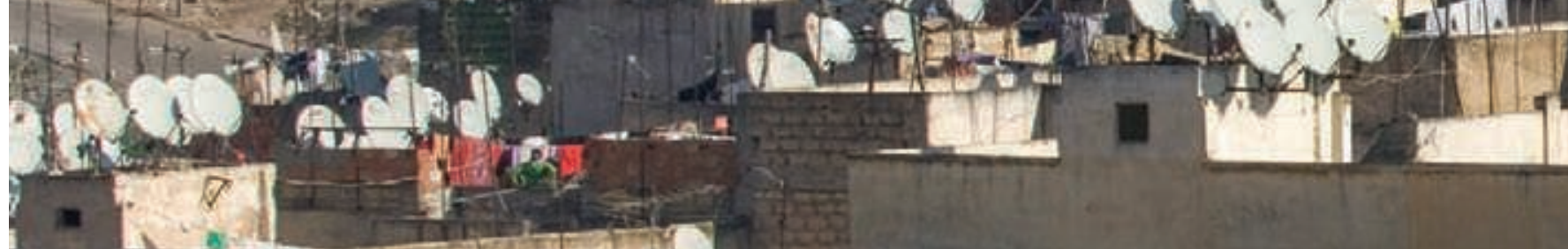

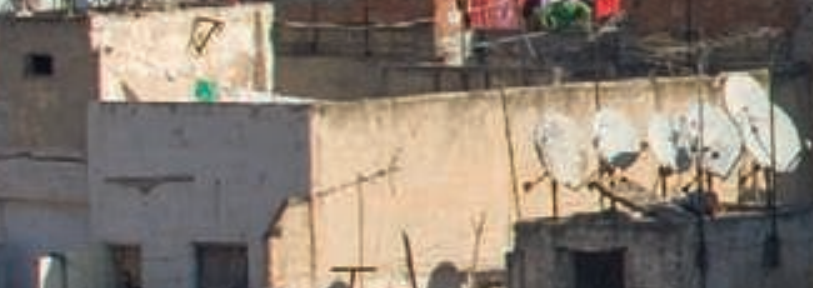

1.1. Thated

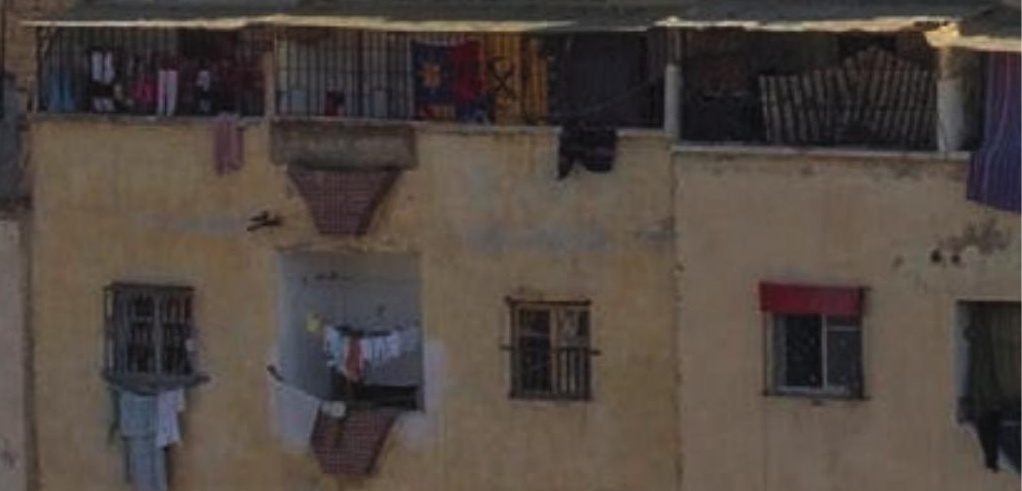

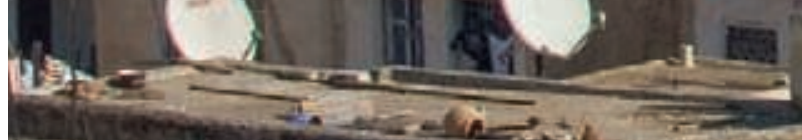
III III

1 .
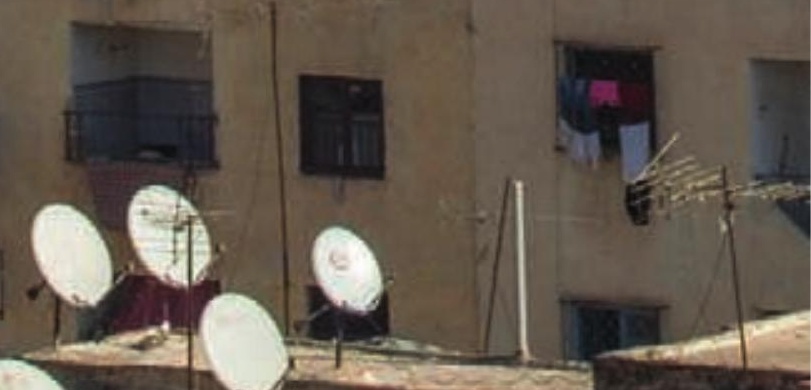


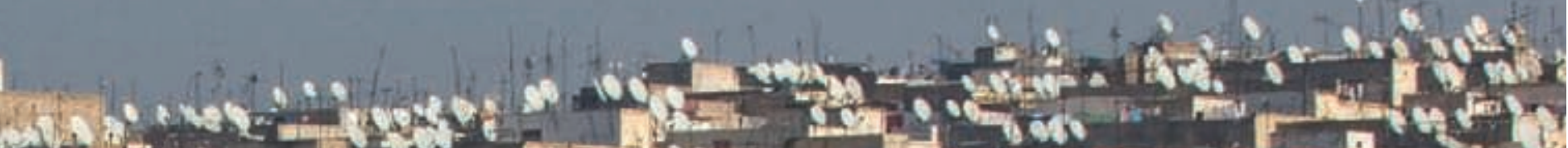

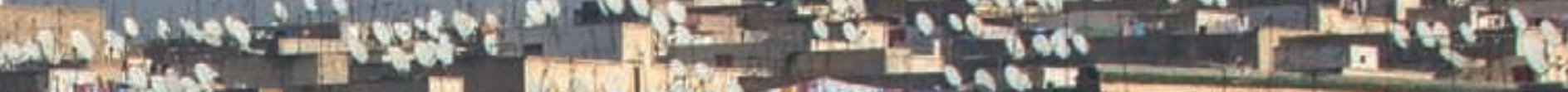

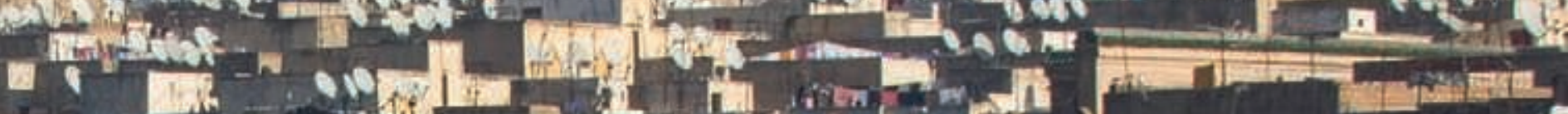

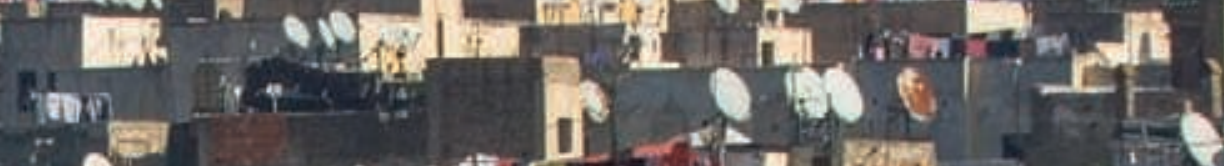

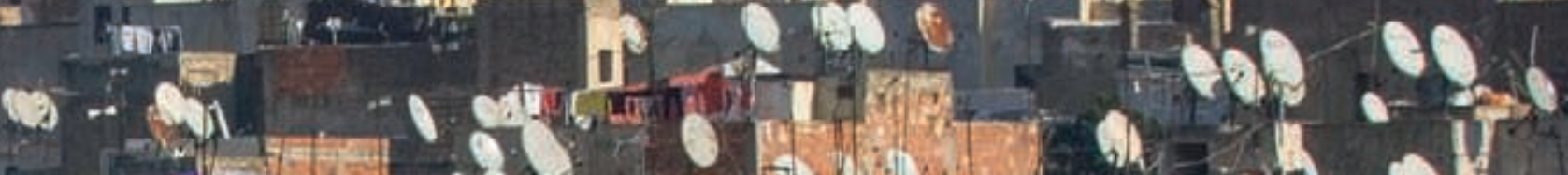
Limand

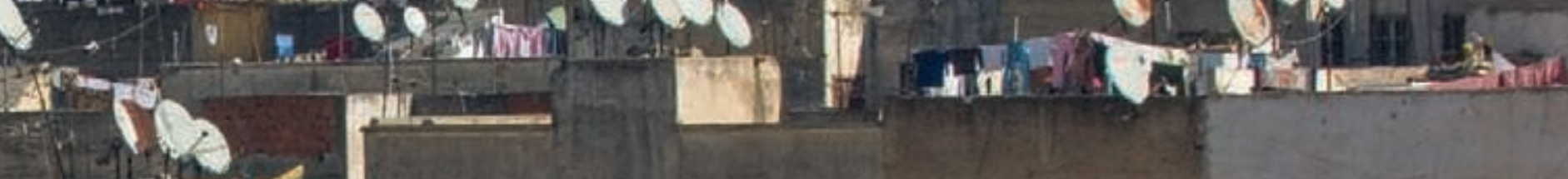

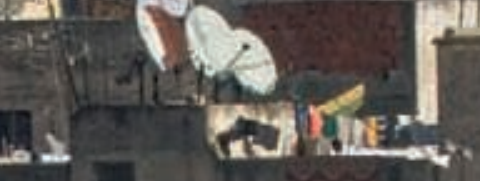

af.

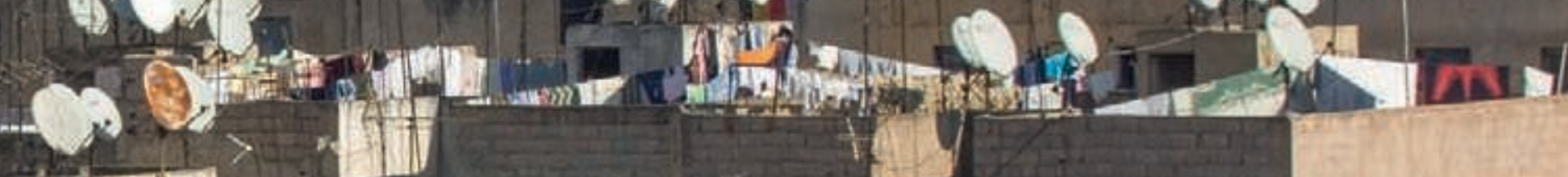
PYI

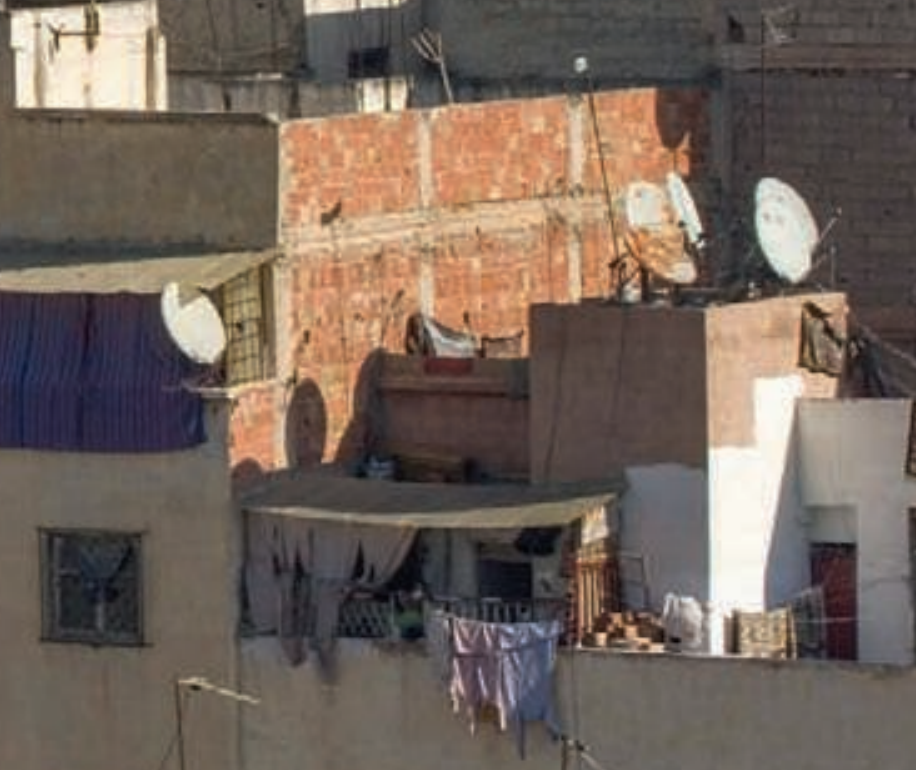

.
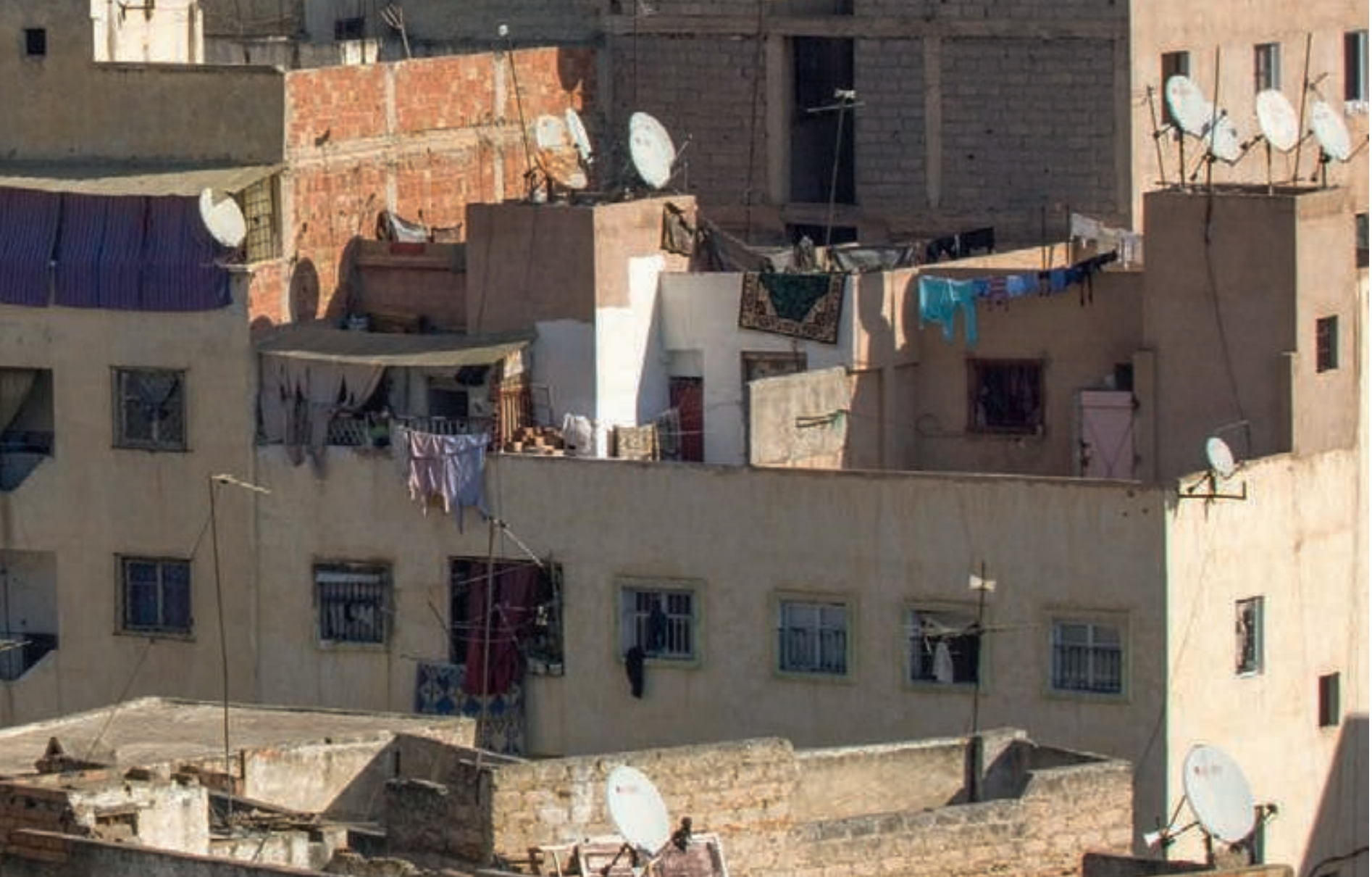
double page précédente

fig. 7

Paraboles sur les toits

de la médina de Fès, 2010

(C) Güner Vahlkampf/Bildenberg. de Fatima Mernissi) et sa décadence actuelle (Fès à vau-l'eau d'Hammad Berrada). De leur côté, élites et fonctionnaires marocains mettent l'accent sur le nécessaire devoir de mémoire. En tant que première capitale du Maroc, lieu d'origine de nombreux politiciens et de pèlerinage vers les mausolées de Sidi Ahmed Tijani et de Moulay Idriss, Fès est une ville importante, pourtant historiquement déconsidérée par les habitants des autres villes marocaines. À cet égard, le Festival des musiques sacrées, le Festival de musique andalouse, le Festival de culture soufie ou encore le Festival d'art culinaire sont, selon les organisateurs, autant de tentatives de renouer avec ce passé prestigieux et de l'inscrire dans le présent. Mais, contrairement à Luang Prabang, les références évidentes au patrimoine colonial semblent avoir été oubliées tant par les résidents marocains que par les membres des institutions chargées du patrimoine. Les bâtiments de la ville nouvelle construite sous le protectorat ne font l'objet d'aucune protection patrimoniale, mais souffrent plutôt d'abandon et de destructions. Seuls certains étrangers et de rares élites marocaines sont attentifs au sort des bâtiments coloniaux. Les grands noms français associés à la préservation du patrimoine sont en passe d'être oubliés. Ainsi Marcel Vicaire, conservateur du musée du Batha et inspecteur des beaux-arts et des monuments historiques à Fès, fut actif dans la préservation de la musique andalouse par la création du groupe de recherche Dar Adyiel, situé dans une demeure du même nom. Pourtant, la plaque explicative de ce monument, aujourd'hui musée de la Musique andalouse, ne mentionne aucunement l'action ni même le nom de Vicaire. Le patrimoine colonial est le grand absent de la description et de la promotion de la richesse culturelle et architecturale de Fès.

\section{Des hyper-lieux fracturés}

L'objectif de cet article était de dégager, par-delà leurs particularités propres, les similarités naissant de la comparaison de deux sites inscrits au patrimoine mondial. Cela va sans dire, Fès et Luang Prabang connaissent des situations très différentes, notamment par leur histoire respective et l'implication concrète de l'Unesco sur place. II faudrait certainement approfondir l'investigation sur l'évolution des politiques patrimoniales de l'Unesco entre 1981 (date de l'inscription de la médina de Fès) et 1995 (date de celle du centre-ville de Luang Prabang) pour expliquer certains des contrastes existant entre les deux villes. Pourtant, des ressemblances se font jour et l'on devrait, à l'avenir, chercher à poursuivre le jeu de la comparaison avec d'autres lieux encore. Irène Bellier a raison de souligner que les organisations internationales, quand bien même elles exportent leur savoir standardisé sur des "terrains locaux", "créent une ineffable impression de déjà-vu» (2011: 100). En diffusant et en entérinant des discours et des pratiques par le biais de ses critères d'inscription, l'Unesco, aujourd'hui acteur incontournable de la patrimonialisation autour du globe, les fixe dans un imaginaire de la préservation qui se traduit notamment par l'utilisation de notions ayant une portée générale (authenticité, intégrité, diversité culturelle, valeur universelle exceptionnelle), mais aussi par des actions patrimoniales concrètes. Un tel imaginaire est réapproprié, avec plus ou moins de succès, par le truchement de politiques nationales ou locales. Alors que des références patrimoniales communes se retrouvent d'un site à l'autre, elles y prennent des formes spécifiques. Souvent, l'Unesco produit sur les sites qu'elle liste un effet de "surclassement», "confirmant l'entrée en 
scène locale de nouveaux groupes d'habitants et d'usagers du monument " (Fabre et luso 2009: 44). Avec le surgissement du patrimoine mondial, les scènes patrimoniales tendent à se complexifier et leurs médiateurs à devenir multiples. Tourisme, relecture de l'histoire, repeuplement, gentrification, spéculations économiques, sentiment de dépossession vécu par les habitants, mais aussi rivalités politiques: la patrimonialisation internationale engendre de nouveaux conflits et enjeux dont les effets sont, pour le meilleur et pour le pire, très réels pour les résidents du lieu. Ils prennent une ampleur remarquable dans des contextes économiquement précarisés, ces lieux pauvres et déclassés se voyant soudainement transformés avec leurs habitants en espaces classés.

À Fès, l'inscription de la médina au patrimoine mondial s'est inscrite dans le mouvement général d'une touristification croissante du Maroc, tandis qu'à Luang Prabang les politiques de l'Unesco ont joué le rôle de déclencheur d'un processus de surclassement. Pourtant, ces deux scènes unescoïsées constituent aujourd'hui des "hyper-lieux", des espaces aux frontières perméables, ouverts aux capitaux étrangers ainsi qu'aux mouvements d'acteurs multiples avec leurs imaginaires propres. Ce qui nous semble particulier à Fès et à Luang Prabang, ce sont les lignes de fracture que la mise en patrimoine internationale a produites, et ce autour de la conception même de patrimoine déployée par les politiques de l'Unesco. Notion étrangère et récente, l'idée de patrimoine «mondial » ne va certainement pas de soi pour nombre d'interlocuteurs locaux qui y voient avant tout les bénéfices du tourisme et ses implications économiques. On pourrait en dire autant de l'authenticité monumentale qui, bien que remise en question par les bureaucrates de l'Unesco, continue d'imprégner les pratiques des experts in situ. Dans la même veine, le choix des monuments listés et des techniques de conservation, résultant de décisions d'experts et de politiciens, entre souvent en conflit avec le rapport de proximité physique et affective que les habitants entretiennent avec «leur » site, affectivité liée à la concrétude banale de leur vie quotidienne plus qu'à la qualité patrimoniale de cet environnement. Au siècle dernier, Walter Benjamin avait déjà posé le dilemme de l'identification patrimoniale en ces termes: "Que vaut [...] tout ce patrimoine culturel s'il n'est pas lié pour nous justement à l'expérience? ” (Benjamin 2011: 40) À comparer les sites de Fès et de Luang Prabang, on voit se dessiner l'un des défis majeurs auxquels l'Unesco s'expose, à savoir comment créer un patrimoine partagé en l'absence d'identification à ses politiques d'héritage.

Laboratoire d'anthropologie des mondes contemporains, Universaité libre de Bruxelles. dberliner@ulbc.ac.be maistass@ulbc.ac.be 


\section{Bellier, Irène}

2011 «Organisations

Internationales", in Francine

Saillant, Mondher Kilani et Florence Graezer-Bideau (dir.), Manifeste de Lausanne. Pour une anthropologie non hégémonique. Montréal, Liber : 99-101.

\section{Benjamin, Walter}

2011 Expérience et pauvreté. Paris, Payot \& Rivages

(«Petite bibliothèque Payot ").

\section{Berliner, David}

2010 «Perdre sa culture.

Les politiques de I'Unesco à Luang Prabang (Lao PDR) ", Terrain 55: 4-19.

\section{1 «Luang Prabang,}

sanctuaire Unesco et paradis gay ", Genre, sexualité et société 5 ; http:// gss.revues.org/index1888.html.

\section{Boym, Svetlana}

2001 The Future of Nostalgia. New York, Basic Books.

\section{Breglia, Lisa}

2006 Monumental Ambivalence. The Politics of Heritage.

Austin, The University

of Texas Press.

\section{Certeau, Michel de}

1990 L'Invention du quotidien. Habiter, cuisiner. Paris, Gallimard.

\section{Cohen, Erik}

1988 "Authenticity and the Commoditization of Tourism " Annals of Tourism Research 15(3): 371-386.

\section{Cousin, Saskia}

2008 "L'Unesco et la doctrine du tourisme culturel. Généalogie d'un bon tourisme", Civilisations 57: 41-56.

\section{Daly, Patrick et Winter, Tim (éd.)}

2011 Routledge Handbook

of Heritage in Asia.

Londres, Routledge.

\section{Detienne, Marcel}

2000 Comparer l'incomparable. Paris, Seuil.

\section{Fabre, Daniel et luso, Anne}

2009 Les monuments sont habités. Paris, Maison des sciences de l'homme ( Cahiers d'ethnologie de la France» 24).

\section{Fontein, Joost}

2006 The Silence of Great Zimbabwe: Contested Landscapes and the Power of Heritage.

Londres-Harare, UCL Press

et Weaver Press.

\section{Geertz, Clifford}

1992 Observer l'islam.

Paris, La Découverte.

\section{Girard, Muriel}

2006 "Imaginaire touristique et émotion patrimoniale dans

la médina de Fès (Maroc) ",

Culture et Musées 8: 61-90.

\section{Gravari-Barbas, Maria et Jacquot, Sébastien}

2008 "Impacts socio-économiques de l'inscription d'un site sur la liste du patrimoine mondial: une revue de la littérature ", in Rémy Prud'homme (dir.), Les Impacts socio-économiques de l'inscription d'un site sur la liste du Patrimoine mondial: trois études. Paris, Unesco: 10-71.

\section{Heinich, Nathalie}

2009 La Fabrique du patrimoine. De la cathédrale à la petite cuillère. Paris, Maison des sciences de l'homme.

\section{Kurzac-Souali, Anne-Claire}

2007 "Rumeurs et cohabitation en médina de Marrakech: l'étranger où on ne l'attendait pas ", Hérodote 4(127): 64-88.

\section{Lahbil Tagemouati, Naïma}

2001 Dialogue en médina. Casablanca, Le Fennec.

\section{McGuinness, Justin}

2006 "Errances vers un Orient imaginaire? Les polymigrants de la médina de Fès (2000-2005) ", IBLA 198: 179-208. 


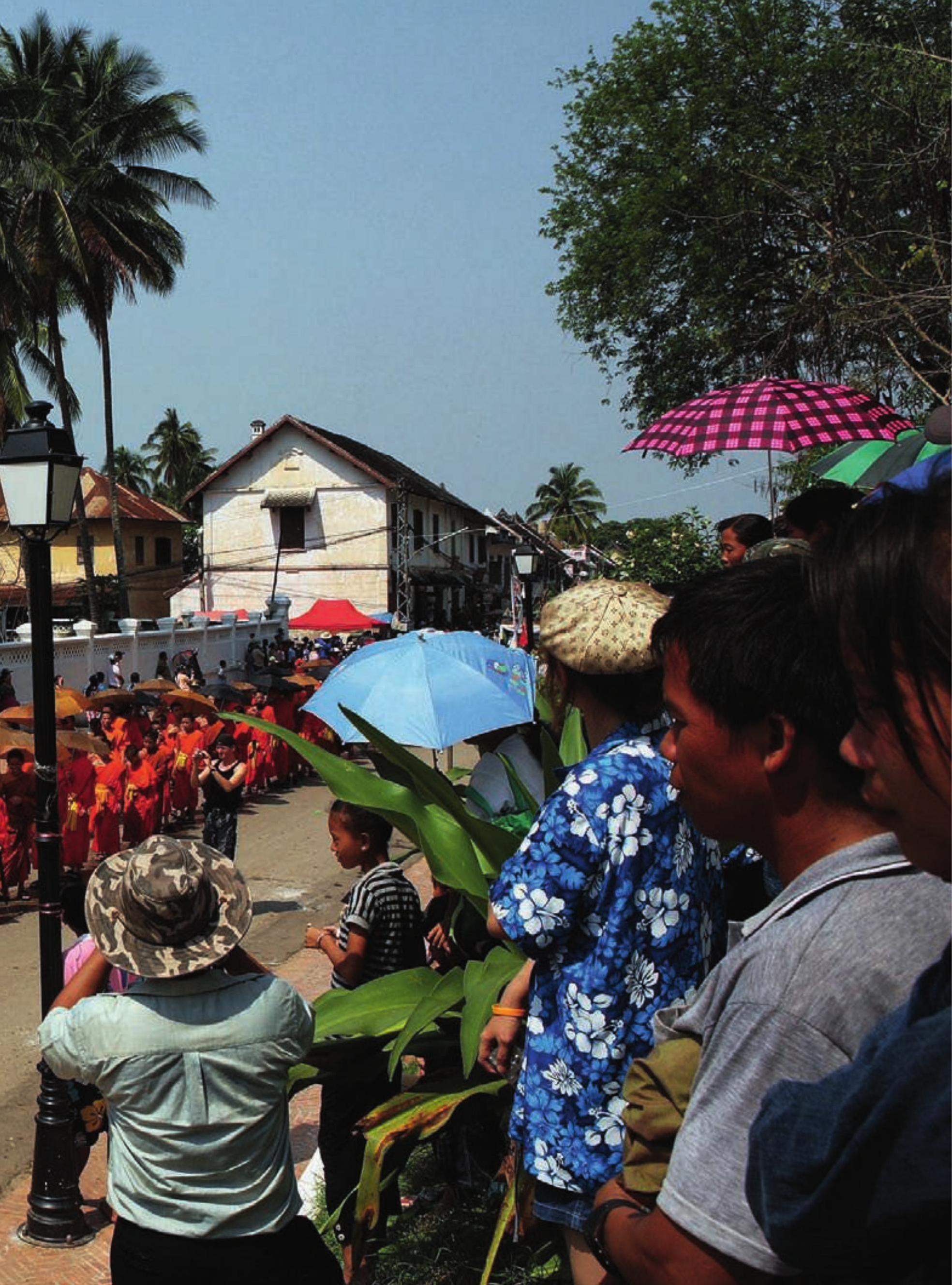

